\title{
Adhesion molecule-modified biomaterials for neural tissue engineering
}

\author{
Shreyas S. Rao ${ }^{1}$ and Jessica O. Winter ${ }^{1,2 *}$ \\ William G. Lowrie Department of Chemical and Biomolecular Engineering, The Ohio State University, Columbus, OH, USA \\ Department of Biomedical Engineering, The Ohio State University, Columbus, OH, USA
}

Edited by:

Wim L. C. Rutten, University of Twente,

The Netherlands

\section{Reviewed by:}

Axel Blau, The Italian Institute of

Technology, Italy

Andre Poot, University of Twente, The

Netherlands

\section{*Correspondence:}

Dr. Jessica O. Winter, William G.

Lowrie Department of Chemical and

Biomolecular Engineering, Department

of Biomedical Engineering, The Ohio

State University, 335 Koffolt

Laboratories, $140 \mathrm{~W} 19$ th Avenue,

Columbus, $\mathrm{OH} 43210$, USA

e-mail:winter.63@osu.edu
Adhesion molecules (AMs) represent one class of biomolecules that promote central nervous system regeneration. These tethered molecules provide cues to regenerating neurons that recapitulate the native brain environment. Improving cell adhesive potential of non-adhesive biomaterials is therefore a common goal in neural tissue engineering. This review discusses common AMs used in neural biomaterials and the mechanism of cell attachment to these AMs. Methods to modify materials with AMs are discussed and compared. Additionally, patterning of AMs for achieving specific neuronal responses is explored.

Keywords: adhesion molecules, neural tissue engineering, biomaterials

\section{INTRODUCTION}

Damage to the central nervous system, which effects at least 2 million people per year (Bani-Yaghoub et al., 2008; Ruff et al., 2008), can be devastating to the patient. Unlike neurons in the peripheral nervous system (PNS), those of the central nervous system (CNS) do not regenerate under normal conditions (Schmidt and Leach, 2003). Several factors contribute to this failure. In the CNS, macrophage recruitment is delayed by the blood-brain barrier, limiting clearance of myelin, a glycoprotein that impedes regeneration. In addition, CNS injury results in activation of astrocytes, a type of glial cell, which proliferate to form an inhibitory glial scar. Several neural biomaterials have been developed as treatment options for CNS injury, and have been used as regenerative, 'tissue-engineered', scaffolds (Langer and Vacanti, 1993) or as components of implanted neural prosthetic devices. These biomaterials are composed of either synthetic or natural materials. Natural materials recapitulate the native environment very well, but manipulating their characteristics may be difficult due to their complex structure. On the other hand, synthetic materials selected for their tunable structural and chemical properties are generally not conducive for neural cell adhesion and hence can impede the process of tissue regeneration.

Researchers have adopted several strategies to improve tissue integration of neural biomaterials, which fall into two general categories: soluble factor addition (reviewed in Willerth and Sakiyama-Elbert, 2007) and modification of materials with tethered biomolecules (i.e., adhesion molecules, AMs). Cell adhesion is an important phenomenon in tissue regeneration. The interaction of the adherent cell with its surroundings can ultimately determine cell fate. For example, it has been shown that cells require a minimal contact area on a substrate to survive (Chen et al., 1997), and that the nature of this contact area can control the formation of connections with the outside environment (Chen et al., 2003).

On an artificial substrate, such as a biomaterial, this proceeds via the following steps (LeBaron and Athanasiou, 2000): (1) initial cell attachment, (2) cell spreading, (3) organization of the actin cytoskeleton and (4) formation of specific focal contacts. The initial attachment of cells onto modified substrates results in immobilization, preventing detachment in response to mild shear forces. Once attached to the surface, the cell membrane begins to spread along the available surface area. This is followed by the creation of a filamentous actin cytoskeleton. Finally, in response to force applied by the cytoskeleton, integrins form clusters, known as focal adhesion sites (Figure 1), that trigger signaling pathways, which can influence cell function, viability, and proliferation (Alberts et al., 1996).

It is well known that cell-cell and cell-extracellular matrix (ECM) interactions are vital for tissue regeneration (Chen et al., 2004; Yu et al., 2008). ECM molecules such as collagen and laminin promote axonal regeneration, differentiation, adhesion, and migration in the central nervous system (Venstrom and Reichardt, 1993). To enhance tissue integration, biomaterials can be modified with short recognition motifs that mimic the ECM to promote cell binding (e.g., proteins, peptides). Incorporating AMs has thus become one of the standard methods for increasing tissue integration of neural biomaterials. This review focuses on strategies to modify biomaterials with AMs for tissue engineering applications in the CNS, and in particular the use of polylysine, collagen, and laminin and their peptide derivatives. In addition, the influence of AM patterning on neuronal behavior is discussed. It should be noted that many of the techniques discussed in this review are equally applicable to other tissue engineering domains (e.g., RGD peptide in bone; LeBaron and Athanasiou, 2000 and cardiovascular tissue engineering; Alobaid et al., 2005), which can serve as a guide for neural biomaterial modification. 


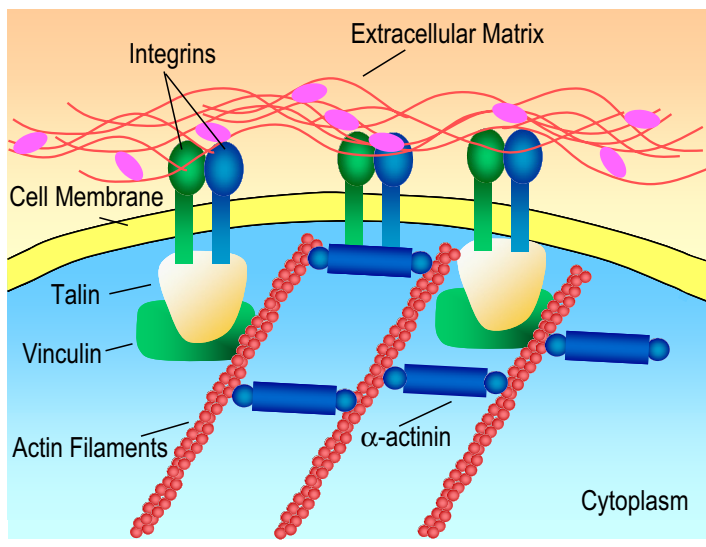

FIGURE 1 | Receptor-mediated cell binding. Figure adapted from http:// www.mun.ca/biology

\section{ADHESION MOLECULES (AMs)}

AMs derived from ECM proteins, including laminin and collagen, initiate receptor-mediated cell binding, inducing the formation of focal adhesions (Figure 1). Focal adhesion sites allow for two-way signal transfer (i.e., into and out of the cell) through an elaborate mechanotransduction system (Hynes, 1999). Specifically, tension in the cytoskeleton can increase integrin receptor affinity for ligand binding (outward signal transfer), and conversely, ligand binding to an integrin receptor can induce a cascade of events within the cell that alters cytoskeletal composition (inward signal transfer). Various focal adhesion proteins assist in this signal transduction cascade, including talin, vinculin, $\alpha$-actinin, filamin and paxillin (Bacakova et al., 2004). This review will focus primarily on integrin-binding AMs (e.g., collagen and laminin). Proteoglycans (PGs), another type of ECM molecule, also mediate cell adhesion using the receptormediated cell binding mechanism. However, PGs are rarely used for neural tissue engineering because they have been shown to have inhibitory effects on axonal regeneration in the CNS (Yu et al., 2008). Additionally, the cell adhesion molecule class of cell surface proteins [CAMs, e.g., neural cell adhesion molecule (NCAM)], which primarily mediate cell-cell interactions, are not commonly used to modify neural biomaterials, and hence are not discussed in this review.

Integrin binding to ECM proteins has been shown to rely on short peptide motifs within the larger protein (Graf et al., 1987; Pierschbacher and Ruoslahti, 1984). Given that large-scale isolation of ECM proteins can be challenging, the application of these specific peptide sequences has received much attention in neural biomaterial modification (Hersel et al., 2003). Peptides are more stable, are more easily synthesized, and are less likely to exhibit steric hindrance after biomaterial modification than whole proteins (Hersel et al., 2003).

For example, the trimer RGD peptide sequence, found in collagen, laminin and fibronectin has been identified as a minimum cell recognition sequence that can mediate adhesion of many cell types, including neurons (Hersel et al., 2003). (It should be noted that in the case of laminin this sequence is not available for binding to integrin receptors until the domains in its vicinity are proteolytically cleaved; Aumailley and Gayraud, 1998). Sequences specific to neural adhesion are found primarily in the ECM molecule laminin, and include YIGSR, IKVAV, RNIAEIIKDI and RYVVLPR. YIGSR, found on the $\beta 1$ laminin chain (Graf et al., 1987) and IKVAV, found on the C-terminal end of the $\alpha 1$ laminin chain (Kleinman et al., 1991 ), bind 67 and $110 \mathrm{kDa}$ proteins on the cell membrane, respectively. The combination of these peptides (Tong and Shoichet, 2001) and extended peptide sequences that incorporate both YIGSR and IKVAV (Yu and Shoichet, 2005) have been found to significantly increase neuronal adhesion. The peptide sequence, RNIAEIIKDI is present on the rlaminin chain (Liesi et al., 1989), whereas RYVVLPR is derived from $\beta 1$ laminin chain (Skubitz et al., 1990).

In addition to laminin, the ECM protein collagen, whose primary function is to provide structural stability to tissues (Gelse et al., 2003), can facilitate adhesion of neural cells through integrins. Most neural cells express integrins belonging to the $\beta_{1}$ and $\alpha_{\mathrm{v}} \beta \mathrm{fam}$ ily (Hersel et al., 2003; Venstrom and Reichardt, 1993). Specifically, $\alpha_{1} \beta_{1}$ integrins can bind collagen type IV and XIII, $\alpha_{2} \beta_{1}$ and $\alpha_{11} \beta_{1}$ can bind fibril forming collagens, whereas $\alpha_{10} \beta_{1}$ can bind type II collagen (Vogel, 2001). (For a detailed description of different types of collagen and their functions the reader is referred to Gelse et al., 2003.) A known integrin-binding peptide sequence that promotes neural adhesion in collagen is DGEA, which is present in collagen type I and fibril forming collagens (Blewitt and Willits, 2007).

In addition to natural biomolecules and peptides, some non-native proteins/peptides have been shown to promote neural adhesion. For example, polylysine, a polypeptide comprised of lysine sequences, enhances neural adhesion, proliferation, and neurite extension (Yavin and Yavin, 1974). Polylysine modulates cell adhesion via a non-receptor-mediated cell binding mechanism (Figure 2). Positive charges on polylysine attract the negatively charged cell membrane resulting in electrostatic bond formation (Yavin and Yavin, 1974). The negative charge on the cell membrane results from the glycocalyx, which is composed of short oligosaccharide chains containing a large number of sialic acid residues (Lauffenburger and Linderman, 1996). It is believed that free polylysine amino groups (Yavin and Yavin, 1974), which produce a monopolar basic surface (Harnett et al., 2007), are necessary for cell adhesion and that adhesion is energy dependant (Yavin and Yavin, 1974) (i.e., adhesion is drastically affected when cultures are exposed to inhibitors of respiration such as cyanide binding reagents). Adhesion is also temperature dependent indicating an affiliation with endocytotic metabolic pathways. Upon binding, polylysine produces a charge-induced redistribution of molecules in the cell membrane, resulting in a 'cell-polylysine interaction' similar to the ligand-receptor-mediated interaction (Rainaldi et al., 1998). Polylysine may also enhance attachment indirectly, by promoting the adsorption of medium proteins (Heggins and Banker, 1998). After the initial, polylysine-induced binding; cells secrete ECM, which is used to initiate mechanotransduction processes described above. It should be noted that cells unable to secrete ECM cannot sustain binding through this mechanism and undergo apoptosis (Bacakova et al., 2004).

Polylysine in both of its forms (i.e., $d$ and $l$ ) mediates neural cell adhesion. Whereas cell responses do not differ greatly, the $d$-form may be preferred over the $l$-form because of its resistance to proteases released in culture (Heggins and Banker, 1998). Another interesting aspect of polylysine is that cell response is drastically altered by changes in the molecular weight (i.e., number of lysine residues). In a red cell model widely used in cell biology and equally 


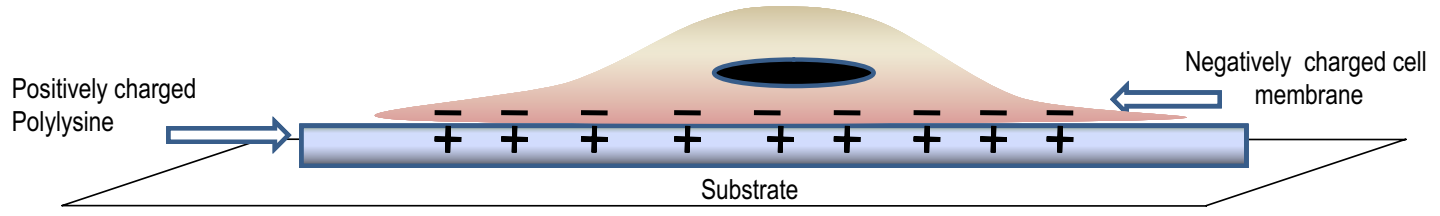

FIGURE 2 | Non-receptor-mediated cell binding.

applicable to neurons, low polylysine concentrations and low molecular weights were found to only weakly promote cells adhesion. At intermediate concentrations and molecular weights, cells spread uniformly. However, high concentrations and molecular weights produced cells lysis (Hategan et al., 2004). These results suggest the importance of selecting polylysine of the appropriate molecular weight and form for the desired application.

\section{APPROACHES TO BIOMATERIAL MODIFICATION SURFACE DEPOSITION}

One of the easiest methods used to modify neural biomaterials is to physically adsorb/coat AMs onto biomaterial surfaces. AMs are physically bound to the biomaterial via weak forces (e.g., van der Waals, hydrogen bonding, electrostatic interaction). This method has been used to apply laminin and polylysine to poly(lactide-coglycolide) (PLGA) films (Park et al., 2008); laminin, polylysine and collagen to polysialic acid hydrogel surfaces (Haile et al., 2008); and laminin to plasma-treated PLGA films, chitosan films (Huang et al., 2007) and poly(L-lactic acid) (PLA) nanofibres (Koh et al., 2008). Although modified biomaterials created using this technique can promote neural cell adhesion, they are limited by poor stability of the AM layer. Additionally, if proteins or long peptide sequences are utilized, physical deposition can create steric hindrance at the active site, lowering adhesion and hence regeneration potential. However, as a first approach to study the effect of AM-modified biomaterials on neuronal response, this technique can provide useful initial data.

\section{BLENDING}

As an alternative to direct adsorption, AMs may be blended with biomaterials to create composites. Blending results in a near uniform distribution of AMs in the biomaterial matrix, is simple and less time consuming than covalent approaches, and provides a more stable material than that formed using adsorption methods. Blended composites can be created as thin films or 3D polymeric constructs. For example, chitosan, a biodegradable polysaccharide obtained from chitin, has been blended with collagen and polylysine to form 2D films (Cheng et al., 2003). These films showed improved neural adhesion over unmodified chitosan, with chitosan-polylysine blends showing the highest adhesion potential. Another study found that films consisting of chitosan- $3 \mathrm{wt} \%$ polylysine supported neural adhesion more effectively than collagen-only films, which have been widely used as adhesive substrate coatings (Mingyu et al., 2004). These films could potentially be applied as coatings for neural prosthetic implants. However, possible disadvantages include instability of AM attachment as a result of non-covalent incorporation, reduction of the number of AMs available per unit surface area with increasing film thickness, and their 2D structure.
As an alternative to thin films, blending can also be used to physically entrap AMs in 3D hydrogel matrices. Hydrogels, insoluble, hydrophilic, cross-linked, polymer networks (Peppas et al., 2006), have been widely studied as brain mimetics because of their structural similarity to glycosaminoglycans (GAGs), which are the primary component of brain ECM. The addition of AMs to hydrogels enhances neural cell adhesion, while preserving a matrix with similar properties to those found in vivo. AM-modification can be used to increase neural adhesion at the interface with tissue (i.e., on the material surface) or to increase adhesion of neurons encapsulated within the hydrogel. For example, laminin blended with a keratin-based hydrogel was used to increase affinity of neurosphere forming cells to the hydrogel surface (2D) (Nakaji-Hirabayashi et al., 2008). Blending can also be used to increase encapsulated cell adhesion; Anseth et al. investigated the effect of collagen-blended with poly(ethylene glycol) - poly(lactic acid) (PEG-PLA) hydrogels on neural cells encapsulated within the 3D hydrogels (Mahoney and Anseth, 2007). AM-modified hydrogels created through blending could be applied to prosthetic devices or used as tissue engineering constructs. In particular, the ability of these materials to recapitulate the $3 \mathrm{D}$ environment found in vivo should yield detailed insights into tissue-level behaviors.

In addition to hydrogels, AMs have also been blended with electrospun fibers to create 3D scaffolds (Koh et al., 2008). Nanostructured scaffolds provide very high surface areas, which may increase the efficacy of AMs as a larger number will be displayed on the surface for the same volumetric loading. Koh et al. have shown that the total amount of AM (i.e., laminin) in blended scaffolds can be higher than that produced by either physical adsorption or covalent modification. Despite this success, results were not comparable with a positive control of polylysine-coated coverslips. It should be noted that these studies are still in nascent stages; different protein molecules at different concentrations were investigated and direct comparison is therefore not possible.

From a manufacturing perspective, blending may be advantageous when compared to covalent modification methods for nanostructured scaffolds. AMs can be incorporated directly during processing (e.g., laminin was present in the electrospinning solution to form laminin-blended electrospun fibers; Koh et al., 2008), rather than requiring subsequent synthesis steps. Postsynthetic modification of 3D porous, nanostructured scaffolds may be challenging because of the difficulty in achieving uniform biomolecule access to the scaffold interior. This becomes more challenging as the scaffold pore sizes approaches that of the biomolecule, limiting diffusion. Blending is less desirable; however, for scaffolds with larger pore sizes. As long as the pore size of the scaffold is less than that of the adhesion molecule, 
AMs can be physically entrapped, preventing their escape, but as pore size increases, biomolecules may diffuse into the surrounding medium.

In general, blending is an attractive method for creating AMmodified materials because of its simplicity. It can be applied to films and 3D constructs, which can serve as prosthetic material coatings or tissue engineering scaffolds. One of the major limitations of blending is the tendency of AMs to escape from the polymer matrix over time. This is mainly caused by the absence of strong attractive forces between AMs and the biomaterial. Several other techniques (e.g., covalent modification) have been explored for developing more stable composite systems.

\section{ELECTROSTATIC ATTACHMENT}

Electrostatic attachment is similar to blending or physical adsorption, but relies specifically on the electrostatic interaction between AMs and the biomaterial as the driving force for biomaterial assembly. Electrostatic attachment methods can be divided into two broad classes: layer-by-layer (LbL) assembly and electrochemical polymerization (Table 1 ).

\section{Layer-by-Layer (LbL) technique (using polyelectrolytes)}

The Layer-by-Layer (LbL) technique involves the deposition of alternating layers of polycationic and polyanionic materials, which can self-assemble through electrostatic attraction to produce nanoscale coatings $(\sim 100 \AA)$. For example, positively charged biomaterials can be electrostatically coupled with negatively charged AMs to produce an alternating structure of (-biomaterial-AM-) $)_{\mathrm{N}}$. The initial deposition of either polycation or polyanion depends on the substrate charge. Fortunately, many likely biomaterial targets for AM-modification are inherently charged. For example, silicon, which is a common material for neural electrodes, has an inherent negative charge and therefore can be coated with polycations. In the event that the target biomaterial does not possess charge, it can be induced by various surface treatment techniques (Peyratout and Dahne, 2004).

The methodology of LbL treatment (Figure 3) is relatively simple (Lutkenhaus and Hammond, 2007; Tang et al., 2006). Initial layer formation proceeds by dipping the negatively or positively charged substrate in alternating polycationic and polyanionic solutions. Between each deposition stage, the excess surface polyelectrolyte is removed by rinsing. This alternate dipping process is repeated until a desired number of bilayers with certain thickness are obtained. Factors that are critical to LbL film formation and stability include $\mathrm{pH}$, polyelectrolyte loading, and ionic strength of the polyelectrolytes. The polyelectrolyte solutions can consist of the biomaterial, other polymers, drugs, or AMs. For optimal performance of AM-modified substrates the terminal layer should contain the AM of interest, permitting direct interaction with cells and tissue.

LbL coatings can be applied to tissue engineering constructs and implanted neural prostheses. Wu et al. demonstrated that LbL films comprised of hyaluronic acid (HA)/collagen promote cortical neuron adhesion on glass (Wu et al., 2007), which is normally a non-permissive substrate. Similarly, Bellamkonda et al. examined LbL films consisting of polyethylimine (PEI)/Laminin, $\mathrm{PEI} / G$ latin/Chitosan/Gelatin, and PEI/Gelatin as neural recording electrode coatings (He and Bellamkonda, 2005). Gelatin is obtained from collagen and is known to promote cell adhesion (Young et al., 2005). These coatings were shown to promote cortical neuronal adhesion and neurite extension in vitro ( $\mathrm{He}$ and Bellamkonda, 2005) (Figure 4) and rapid reduction of early microglia activation (over a period of 4 weeks) (He et al., 2006) in vivo. This implies that LbL coatings can lower immune response over a stipulated time period.

LbL films have many advantages. They are versatile and can be applied to virtually any charged substrate. They can achieve near conformal coatings, with nm control of thickness. However, their long term stability in vivo is still questionable. Films are $\mathrm{pH}$ sensitive, with even minor changes in $\mathrm{pH}$ altering organization and producing instability. Instability might possibly be addressed

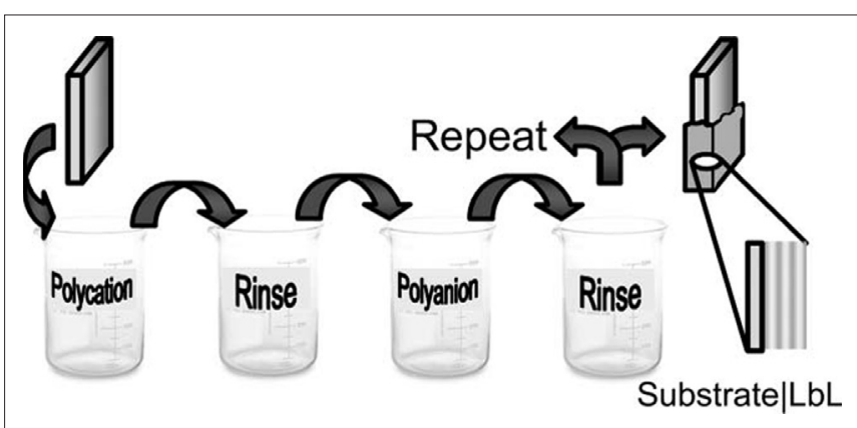

FIGURE 3 | Schematic of LbL technique. Reproduced by permission of the Royal Society of Chemistry (Lutkenhaus and Hammond, 2007).

Table 1 |Advantages and disadvantages of electrostatic attachment techniques.

\begin{tabular}{|c|c|c|}
\hline $\begin{array}{l}\text { Techniques utilizing electrostatic } \\
\text { attachment }\end{array}$ & Advantages & Disadvantages \\
\hline LbL assembly (using polyelectrolytes) & $\begin{array}{l}\text { - Better control of film thickness } \\
\text { - Simple technique }\end{array}$ & $\begin{array}{l}\text { - Lack long term stability } \\
\text { - Highly pH sensitive }\end{array}$ \\
\hline $\begin{array}{l}\text { Electrochemical polymerization } \\
\text { (using conducting polymers) }\end{array}$ & $\begin{array}{l}\text { - Thin films can be obtained } \\
\text { - Doping of AM and polymerization occur at } \\
\text { the same time } \\
\text { - High surface area can be achieved for } \\
\text { neural interfacing }\end{array}$ & $\begin{array}{l}\text { - Limited to monomers that oxidize under the influence of } \\
\text { applied potential } \\
\text { - Modifying the bulk of conducting polymer after } \\
\text { electrochemical polymerization may be difficult }\end{array}$ \\
\hline
\end{tabular}



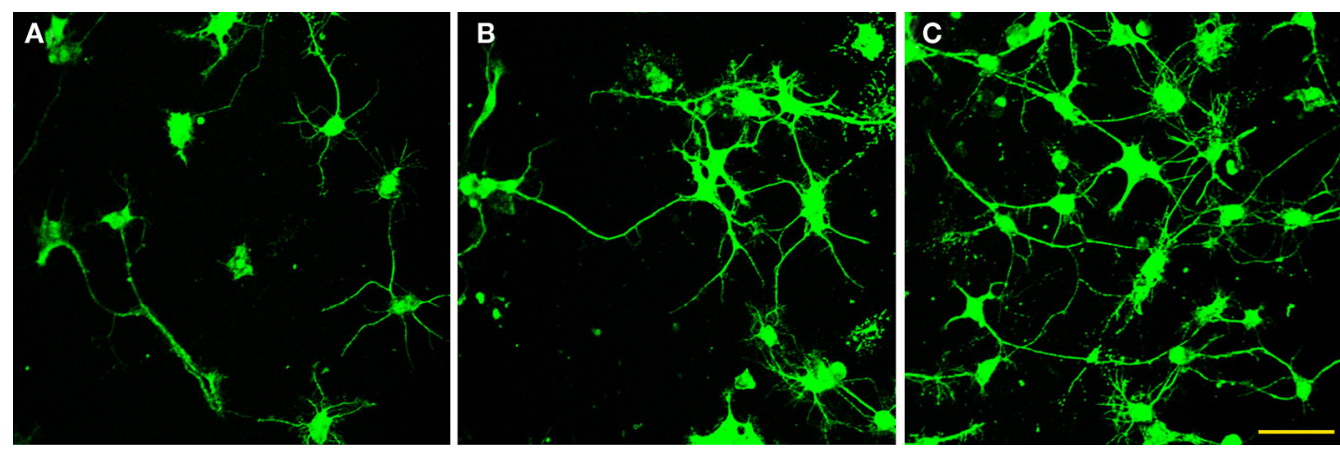

FIGURE 4 | Immunofluorecence of chick cortical neurons on Si wafers (5 days). (A) (PEl-Gelatin) ${ }_{8^{\prime}}$ (B) (PEl-gelatin)-(Chitosan-gelatin) ${ }_{7}$ (C) (PEI-Laminin) ${ }_{8}$ (Figure courtesy: Dr. Ravi Bellamkonda, Georgia Institute of Technology and Dr. Wei He, University of Tennessee.)

by cross-linking polyelectrolyte layers either chemically or via photocoupling. This could enhance their stability due to the presence of multiple linkages (i.e., electrostatic as well as cross-linking), but complicates material processing.

Furthermore, since LbL assembly is mainly charge based, it is necessary for the AM to possess sufficient charge opposite that of the biomaterial for coupling to occur. For instance, gelatin is available mainly as Type A (obtained from porcine skin) and Type $\mathrm{B}$ (obtained from bovine skin). The isoelectric points of gelatin range from 4.5 to 9.4 with Type A having a higher isoelectric point (7-9.4) compared to Type B (4.5-5.3) (Poppe, 1997). The type of gelatin selected and the experimental conditions chosen should be adjusted to reflect the charge of the biomaterial to be modified. Similarly, cell response to different types of gelatin may also vary with charge presented at the physiological $\mathrm{pH}$ and should be considered.

\section{Electrochemical polymerization (using conducting polymers)}

Another class of biomaterials that can incorporate AMs through electrostatic interactions is electrically conducting polymers. Because nerve cells are electrically active, there is great interest in using electrically conducting biomaterials to more closely mimic the native neural environment. One of the most extensively studied conducting polymers is polypyrrole (PPy), a heterocyclic conducting polymer, which promotes neurite outgrowth under the influence of electrical stimulation (Schmidt et al., 1997). Ppy has also been utilized for drug delivery (Li et al., 2005), neural probe coatings (Cui et al., 2001, 2003; George et al., 2005; Kim et al., 2004; Stauffer and Cui, 2006) and bioactuation (i.e., the generation of a mechanical force as required in artificial muscle actuators) (Gandhi et al., 1995; Spinks et al., 2005a,b).

Electrically conducting polymers consist of charged crystalline to semi-crystalline polymer chains that are doped with ions of the opposite charge. Dopants serve to balance the charge of the conducting polymer to produce a neutral composite. Charged AMs can be incorporated into electrically conducting polymers as dopants using electrochemical polymerization (Figure 5) (Guimard et al., 2007). For example, a neutral polymer such as Ppy develops a positive charge following oxidation and can be coupled with negatively charged AMs during electrochemical polymerization. In this process, a three electrode system is typically employed. The apparatus consists of a working electrode (where the films deposited, usually Si for neural probes, ITO for other applications), a counter electrode (e.g., platinum) and a reference electrode (e.g., calomel electrode) in a liquid solution of monomer and dopant in a suitable solvent. Applying electric current to the system produces conducting polymer/AM film deposition on the working electrode surface. Polymer monomers undergo oxidation at anodic sites forming cations that can bind negatively charged dopants (e.g., AMs). The resulting composite thus has a net charge of zero. Film thickness is controlled by the amount of charge that passes through the electrode system. Parameters that can influence film topography and conductivity include deposition time, temperature, electrode system, and choice of solvent. The technique is straightforward and attractive because doping of AM and polymerization proceed simultaneously. Also, extremely thin films $(\sim 20 \mathrm{~nm})$ can be prepared.

This method has been used to dope polypyrrole with CDPGYIGSR (Figure 6), an extended peptide sequence from laminin, on gold recording sites of Si-neural recording probes (Cui et al., 2001). In vitro, these materials demonstrated increased neuroblastoma cell adhesion compared to control films (Figure 7). In vivo, the coatings have been shown to be stable for at least 1 week and to promote neural adhesion (Cui et al., 2003). In later work, PPy/RNIAEIIKDI (a sequence from laminin) coatings were shown to be superior to the original PPy/CDPGYIGSR composites in promoting neural adhesion and axonal growth (Stauffer and Cui, 2006), demonstrating the importance of AM selection when creating modified biomaterials. This work has also been extended to other conducting polymers, for example poly(hydroxymethylated-3, 4-ethlenedioxythiophene) (PEDOT$\mathrm{MeOH}$ ) has been doped with the laminin fragment CDPGYIGSR (Xiao et al., 2006).

As an alternative to using AMs directly as dopants, other entities can be employed to tether the AM to the conducting polymer through the dopant. One advantage of this method is that different AMs can be incorporated onto the same 'base' material (i.e., conducting polymer/dopant composite). Song et al. (2006) used this method to tether polylysine and laminin to PPy doped with poly(glutamic acid) (Ppy/PGlu). Specifically, Ppy was doped with PGlu using electrochemical polymerization. Polylysine and laminin were then attached to the resulting Ppy/PGlu composite 


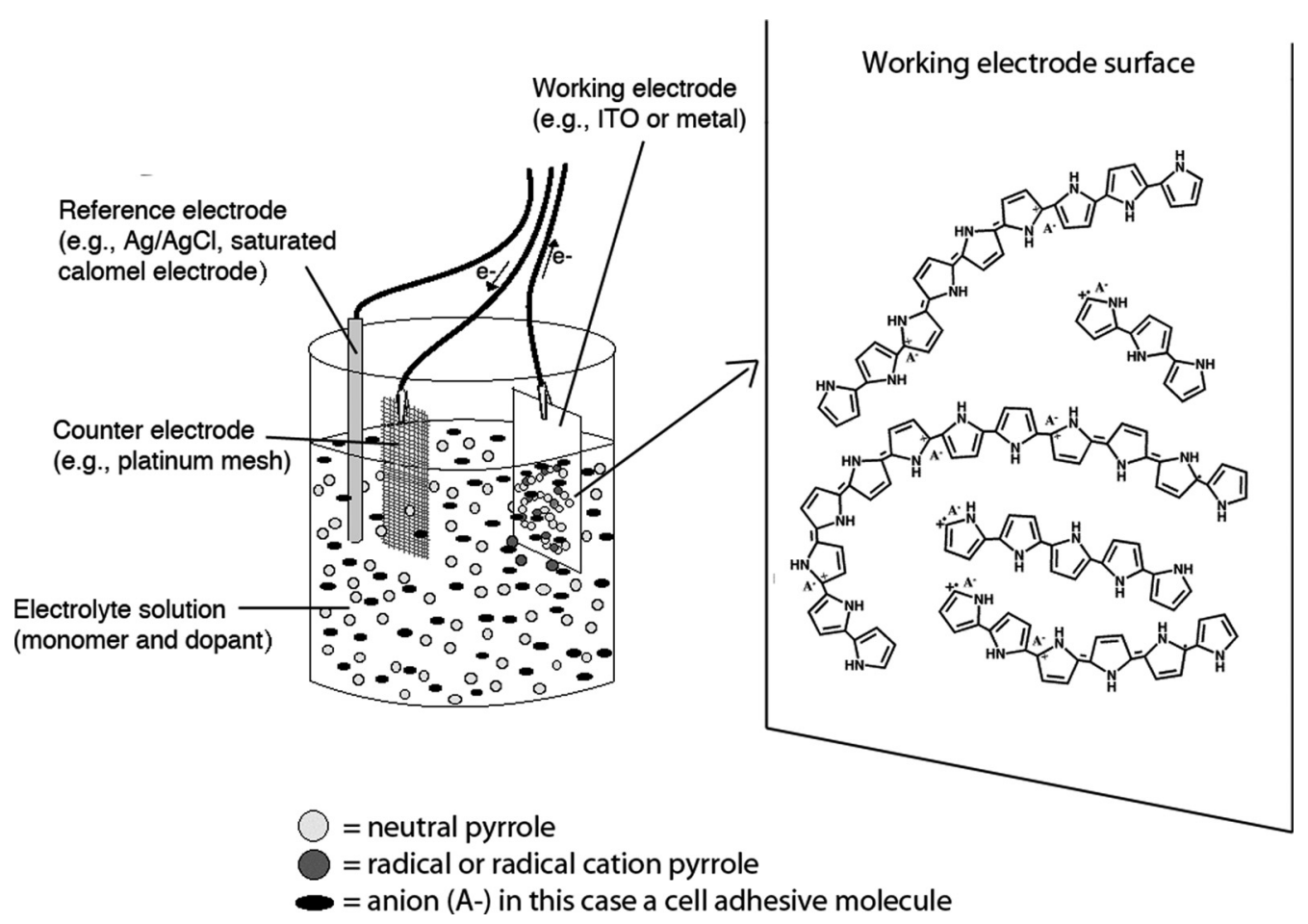

FIGURE 5 | Electrochemical polymerization. (Figure courtesy of Nathalie Guimard and Dr. Christine Schmidt, The University of Texas at Austin.)

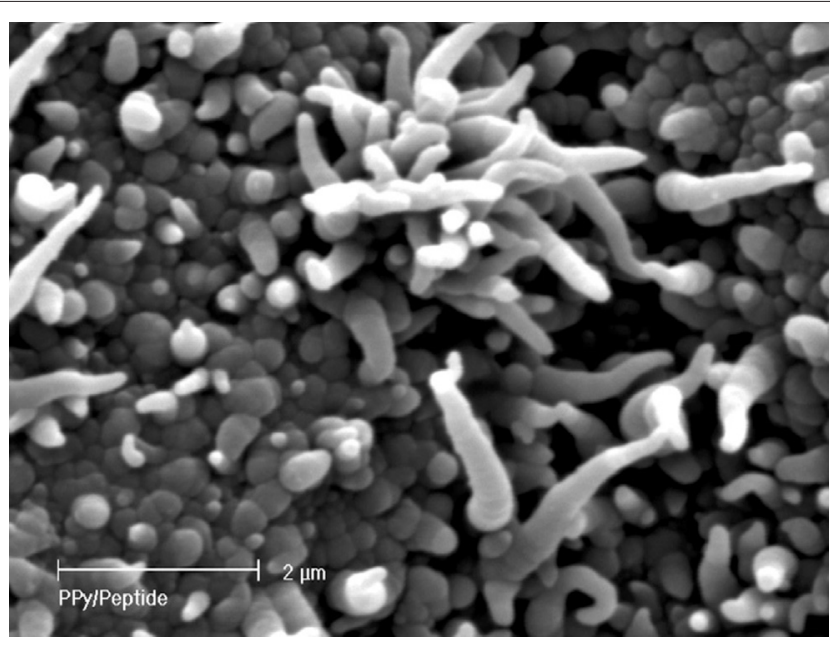

FIGURE 6 | SEM of PPy/CDPGYIGSR on a microelectrode site of a neural probe (Cui et al., 2003). Scale bar = 2 micron. Reprinted with permission of Elsevier Ltd. @ 2002 Elsevier Ltd.

by a covalent bond formed between PGlu and AMs using EDC chemistry (see below, covalent binding).

AM electrochemical incorporation into conducting polymers has specific advantages for neural prosthetic systems. Because the composites are films, they provide high surface area, and therefore high AM contact area. Although not specific to AM-modified materials, the high surface areas of electrically conducting polymer films also provide ample sites for Faradaic charge transfer, the

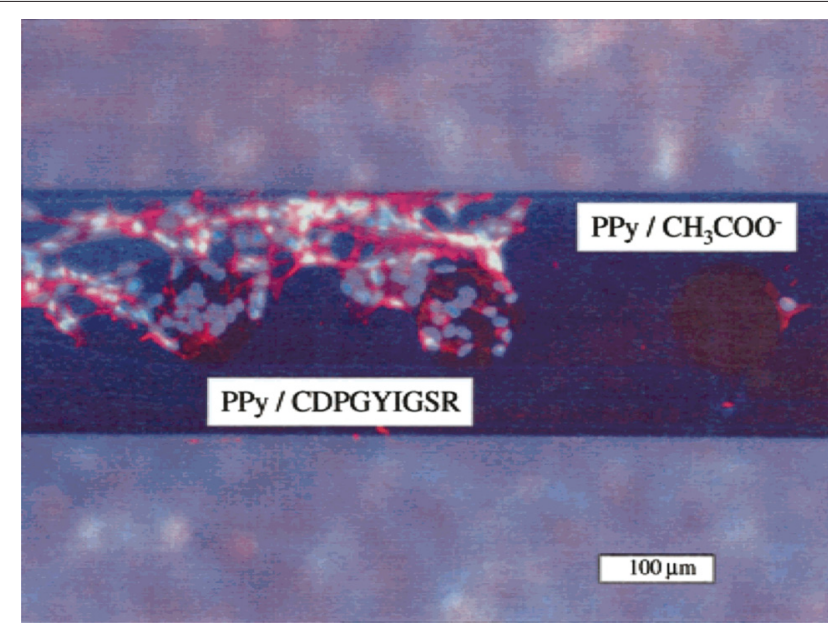

FIGURE 7 | Neuroblastoma cell response on a coated neural probe (Cui et al., 2001). Reprinted with permission of John Wiley \& Sons, Inc. (C) 2001 John Wiley \& Sons, Inc.

primary mode of electrical conduction in implanted prostheses. Faradaic charge transfer depends on the storage capacity of the material, and in the case of surface reactions, on the surface area of the material. In addition to electrical considerations, composite surface properties, namely morphology and conductivity, could potentially be precisely tuned to encourage neurons to form firm contacts with the electrode, while minimizing the activation of astrocytes, a sign of immune response. However, despite extensive 
study of these composites, long term stability continues to be a major impediment to the use of conducting polymer-AM composites for neural interfaces. For instance, it has been observed that PPy undergoes structural changes and is subject to degradation in vivo within short time periods (Xiao et al., 2006). Alternative conducting polymer materials are being explored to address this problem.

\section{COVALENT ATTACHMENT}

Techniques based on weak interactions (i.e., physical adsorption, blending) often fail to strongly bind AMs to biomaterial scaffolds, which can permit escape via diffusion. This is disadvantageous, especially for in vivo applications in which the implanted material may be intended for months or years of use. Covalent binding of AMs to biomaterials can produce much more stable composites. Several covalent attachment techniques have been designed specifically for biomaterial modification (see Hermanson, 1996 for details). This review will concentrate on attachment methods mediated by thiol, amine, carboxylate and hydroxyl linkages, as these have been most commonly employed (Table 2 ). It should be noted that some of these techniques require pretreatment of surfaces to produce the desired surface functionalization; however, these methods (e.g., plasma treatment, ionizing radiation graft copolymerization; Ratner et al., 2004) are beyond the scope of this review.

Table 2 | Covalent coupling of AM with biomaterials.

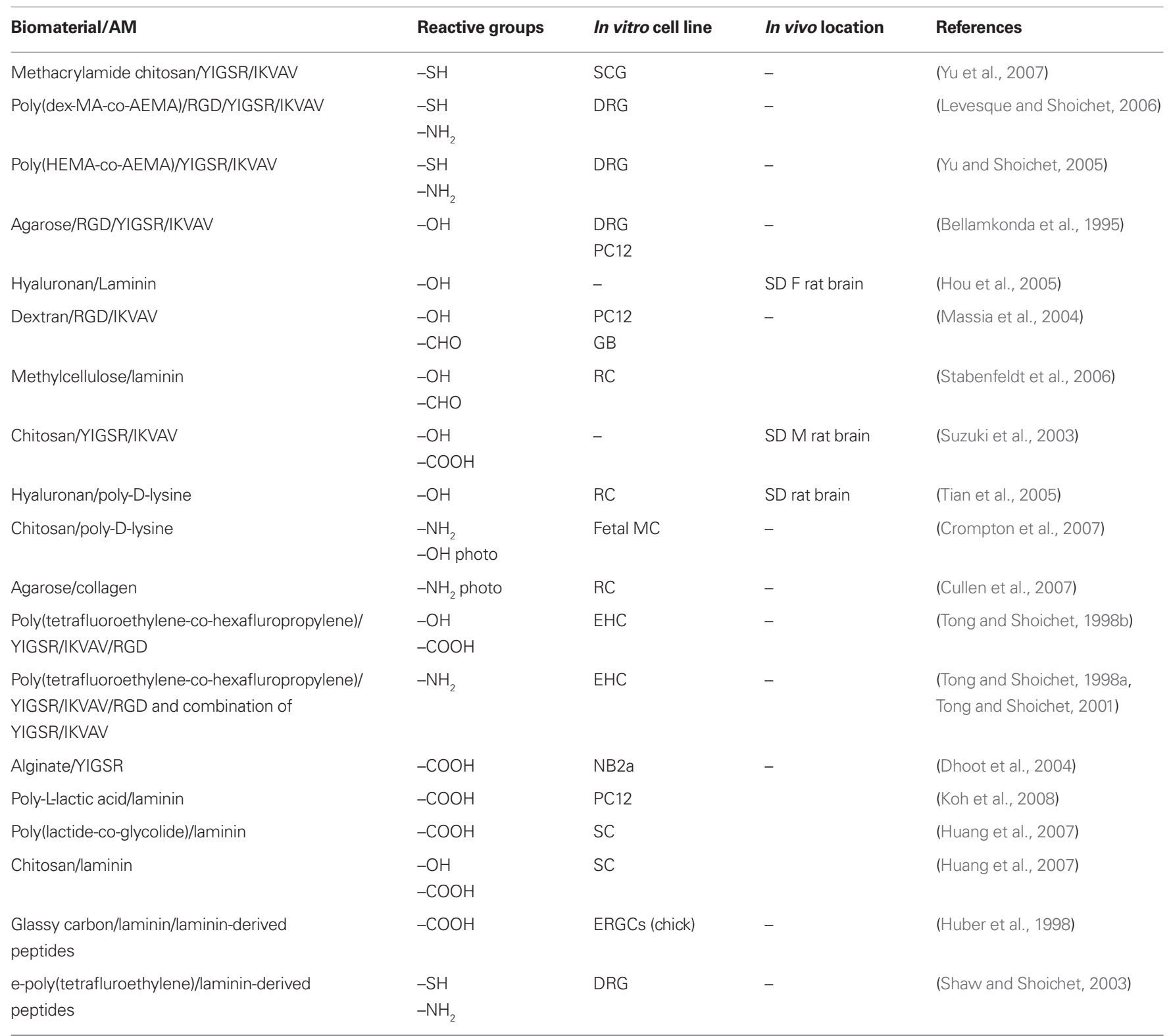

DRG: dorsal root ganglion, SCG: superior cervical ganglion, SC: Schwann cells, RC: rat cortical neurons, MC: mouse cortical neurons, EHC: embyronic HippoAMpal neurons, ERGC: embryonic retinal ganglion cells, GB: glioblastoma, SD: Sprague Dawley, F: female, M: male. 
Chemical modification mediated by thiol $(-\mathrm{SH})$ groups involves the reaction of a sulfhydryl compound with a maleimide derivative to form a thioether bond (Scheme 1) (Hermanson, 1996). This route has been used by the Shoichet group (Yu et al., 2007) to conjugate cell adhesion peptides CDPGYIGSR and GQASSIKVAV (both laminin derived) to thiolated methacrylamide chitosan scaffolds. Other approaches employing similar chemistry use heterofunctional crosslinkers to conjugate AMs to biomaterials. Intermediary crosslinkers are generally preferred to direct biomolecule conjugation because the crosslinker separates the biomolecule from the biomaterial, reducing steric hindrance and preserving the conformation of the protein or peptide. The choice of the cross-linking agent is dependent on application. For example, for in vivo use, a cross linker that minimizes immune response should be chosen. One commonly examined -SH active crosslinker is sulfo-SMCC [sulfosuccinimidyl-4-(N-maleinidomethyl) cyclohexane-1-carboxylate] (Scheme 2), which has an amine-reactive NHS ester as well as a thiol reactive maleimide.

This cross linker has been used to conjugate CRGDS and CDPGYIGSR/CQAASIKVAV to poly(methacrylated dextranco-amino ethyl methacrylate) [p(dex-MA-co-AEMA)] (Levesque and Shoichet, 2006), CDPGYIGSR/CQAASIKVAV to poly(hydroxyl ethyl methacrylate-co-2-aminoethyl methacrylate) [p(HEMAco-AEMA)] (Yu and Shoichet, 2005), and CYIGSR/CDPGYIGSR/ CIKVAV/CQAASIKVAV to e-poly(tetrafluroethylene) (Shaw and Shoichet, 2003). Cell adhesion was improved for all AM-modified biomaterials when compared to unmodified control biomaterials (e.g., Figure 8).
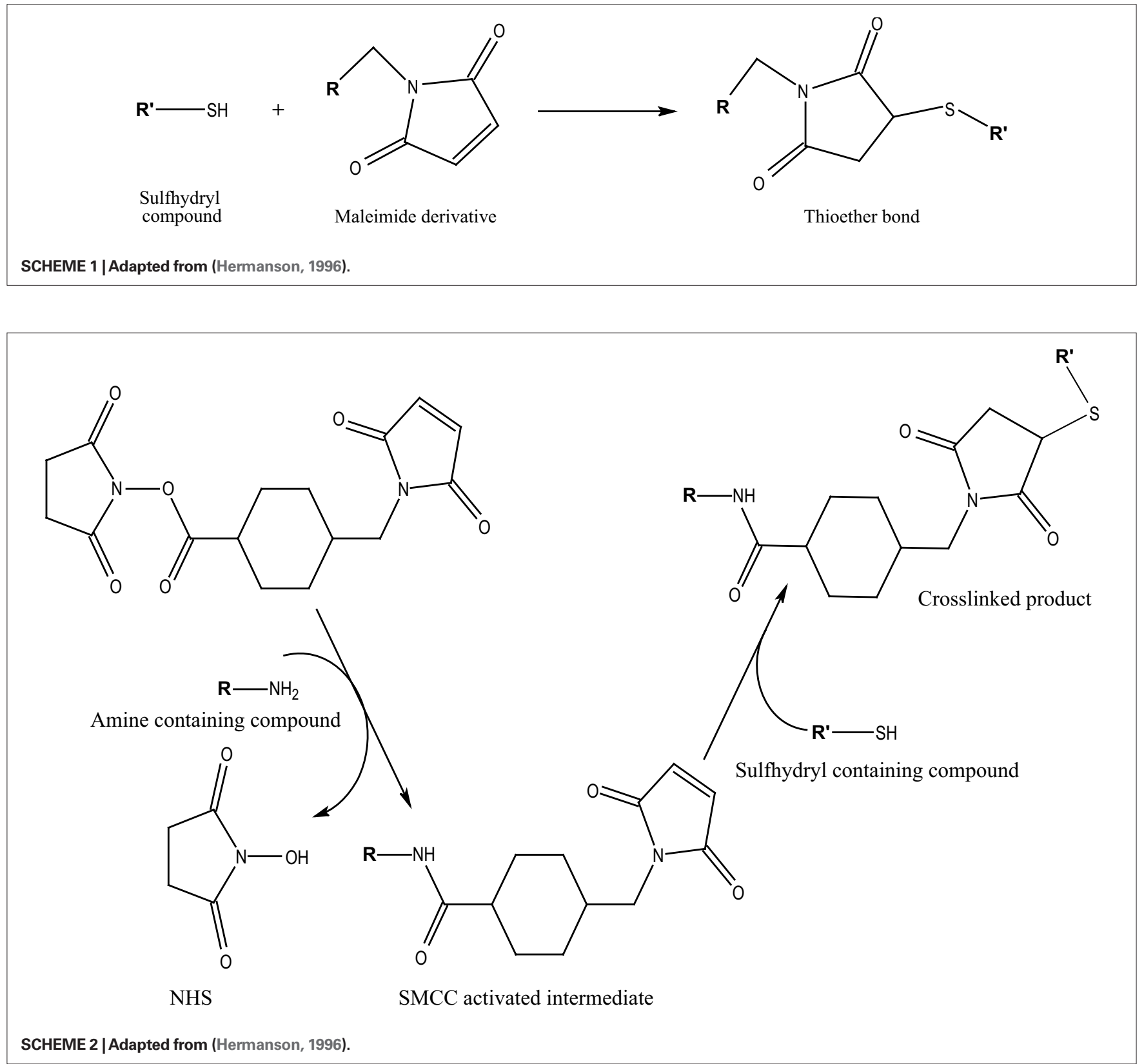
Many polymers used for neural engineering applications contain hydroxyl groups (-OH) (e.g., agarose, hyaluronan). Carbonyldiimidazole (CDI) chemistry can be exploited to couple biomaterials with AMs via a hydroxyl mediated reaction (Scheme 3).

CDI, a carbonylating agent with acylimidazdole groups can react with $(-\mathrm{OH})$ containing biomaterials to form imidazole carbamate active intermediates. These intermediates further react with amine containing compounds releasing imidazole, thus forming stable carbamate linkages (Hermanson, 1996). Bellamkonda et al. (1995) used this chemistry to covalently couple agarose to laminin

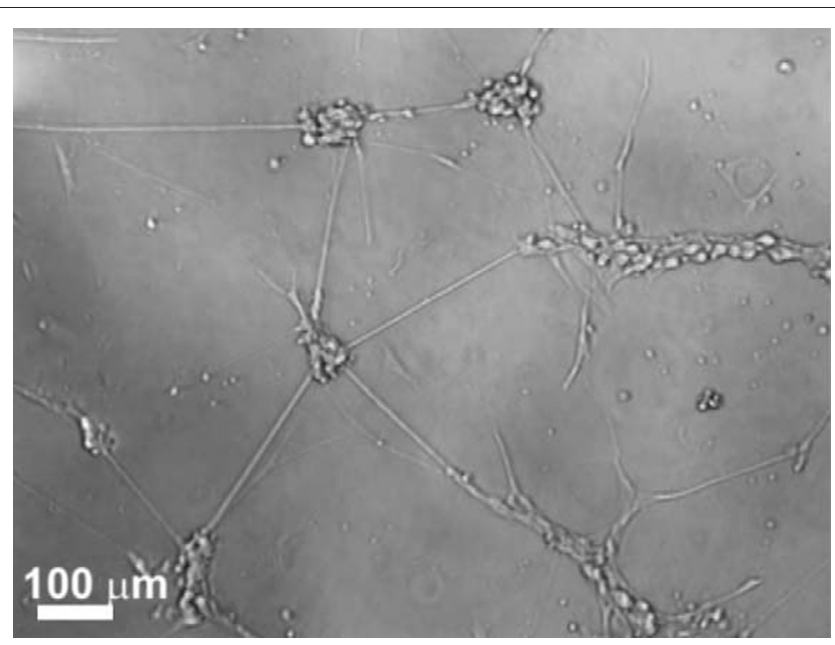

FIGURE 8 | Representative light microscope image of DRG neurons on poly(Dex-MA-co-AEMA) modified with CGRGDS (Levesque and Shoichet, 2006). Reprinted with permission of Elsevier Ltd. @ 2006 Elsevier Ltd. fragments (CDPGYIGSR, IKVAV, GRGDSP and their combination). This method has also been used to bind laminin to hyaluronan (Hou et al., 2005).

It is also possible to target hydroxyl groups via periodate oxidation (Hermanson, 1996) wherein compounds containing internal diol groups, terminal diol groups or terminal hydroxylamine groups can be oxidized to form aldehydes (Scheme 4).

Aldehydes can then react with amine compounds to form a Schiff base (imine). This approach has been used to covalently bind laminin fragments to dextran (Massia et al., 2004) and to bind laminin to methylcellulose (Stabenfeldt et al., 2006).

Perhaps the most popular method used for covalent biomaterial modification is EDC chemistry, which proceeds via reaction with carboxylate (-COOH) groups. EDC or EDAC [1-ethyl-3-(3dimethylaminopropyl) carbodiimide hydrochloride] is a water soluble, zero length cross linker. Generally, EDC is used to covalently link a carboxylate $(-\mathrm{COOH})$ or a phosphate $\left(-\mathrm{PO}_{4}\right)$ compound with an amine $\left(-\mathrm{NH}_{2}\right)$ (Scheme 5).

Carboxylates react with EDC to form o-acylisourea intermediates, which in turn react with amine compounds to form stable amide bonds and isourea as a byproduct. This byproduct can be easily separated from the product since it is water soluble (Hermanson, 1996). It may be necessary to use sulfo-N-hydroxysuccinimide (sulfo-NHS) in conjunction with EDC if the intermediate product is highly unstable (e.g., hydrolyzed) or if the amine compound is present in low concentrations. Addition of sulfo-NHS forms sulfo-NHS ester intermediates that are more stable and can efficiently react with amine compounds, increasing conjugation yields. A disadvantage of using EDC is that some target biomolecules (e.g., peptides) contain both carboxylate and amine groups, which can produce self-polymerization rather than conjugation to the desired biomaterial (Hermanson, 1996).

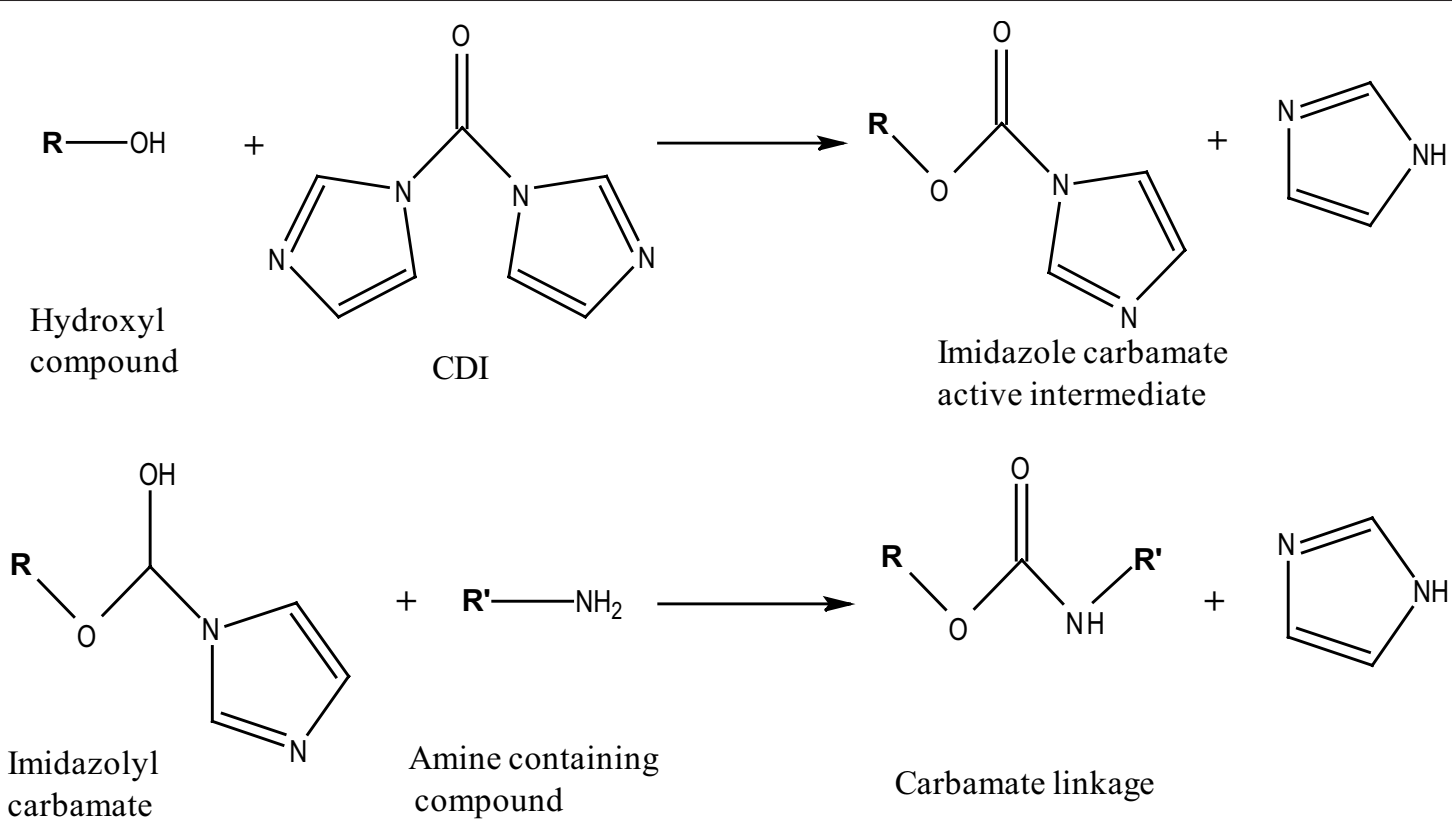

SCHEME 3 | Adapted from (Hermanson, 1996). 
<smiles>[R]CC(O)C(O)C[R]</smiles>

Compound with an internal diol group<smiles>[R]CC(O)CO</smiles>

Compound with terminal diol group<smiles>[R]C(=O)C(N)CO</smiles>

Compound with

terminal hydroxylamine group<smiles>[R]CC([CH3+])[O-]</smiles>

Aldehyde<smiles>[R]CC([CH2+])=O</smiles>

Aldehyde<smiles></smiles>

Aldehyde

SCHEME 4 | Adapted from (Hermanson, 1996).

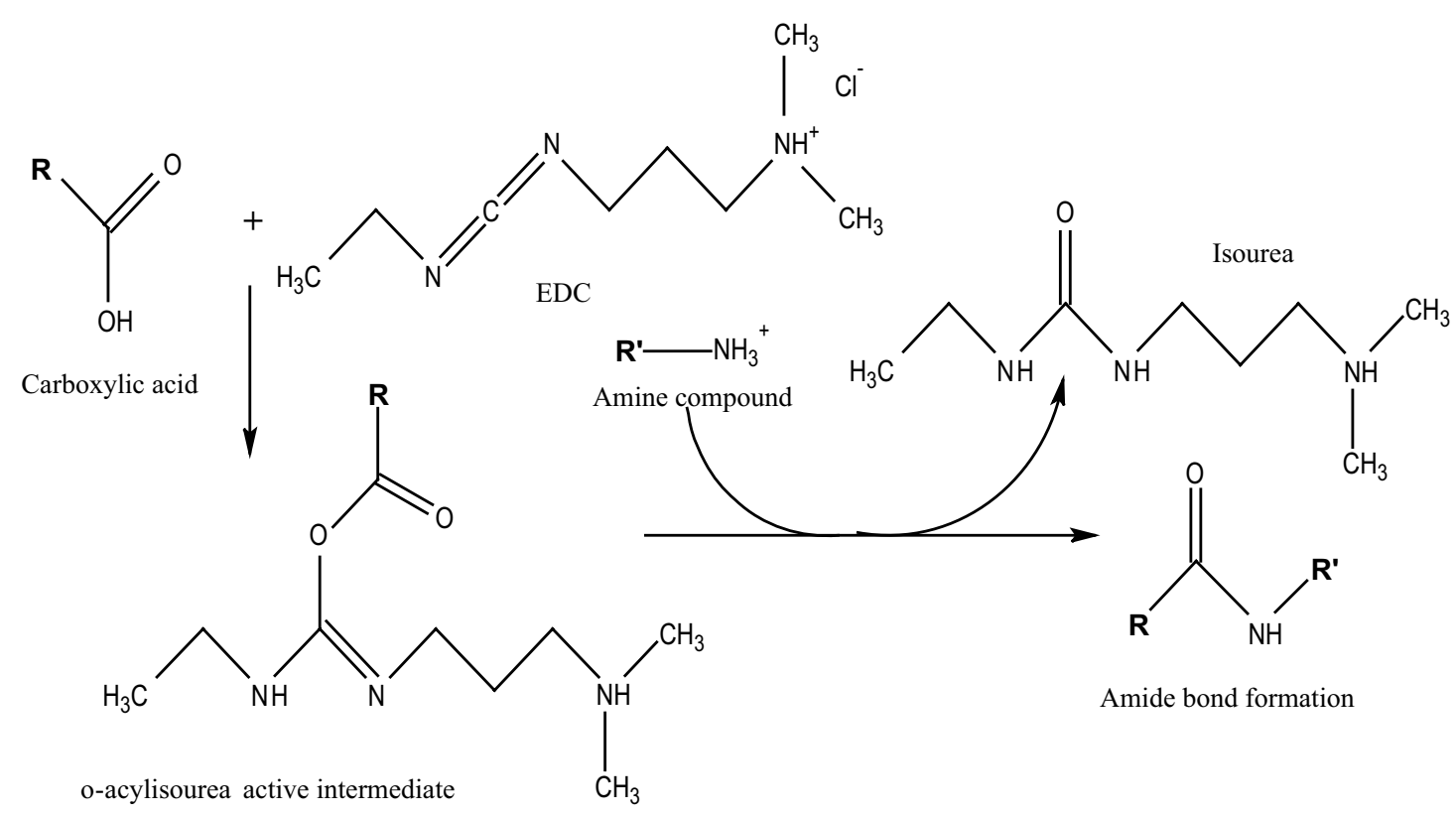

SCHEME 5 |Adapted from (Hermanson, 1996). 
EDC chemistry has been widely employed in neural biomaterial modification. For example, it has been used to covalently modify chitosan with laminin-derived peptides (Suzuki et al., 2003), poly-D-lysine with hyaluronan (Tian et al., 2005), alginate with YIGSR (Dhoot et al., 2004), PLGA and chitosan with laminin (Huang et al., 2007), aminated glass with various integrinbinding peptide sequences (Kam et al., 2002), and glassy carbon implant materials with laminin peptide sequences (Huber et al., 1998). Recently, Koh et al. (2008) also showed that EDC chemistry can be used to modify electrospun poly(L-lactic acid) fibers with laminin.

In addition to these more common cross-linking methods, carboxyl $(-\mathrm{COOH})$ and hydroxyl $(-\mathrm{OH})$ groups have also been covalently modified with tresyl chloride, SMCC and O-(N-succinimidyl)-N,N, $\mathrm{N}^{\prime}, \mathrm{N}^{\prime}$-tetramethyluronium tetrafluoroborate. This method was used to couple laminin-derived peptides to poly(tetrafluroethylene-co-hexafluoropropylene) (FEP) (Tong and Shoichet, 1998b). Specifically, FEP was functionalized with reactive groups (i.e., hydroxyl or carboxyl) by a sequence of chemical reactions and covalently coupled to peptides using one of the aforementioned coupling agents. As an alternative, introducing amine functionality to FEP surfaces and coupling laminin peptides (Tong and Shoichet, 1998a) and their combination (Tong and Shoichet, 2001) was also investigated.

Apart from purely chemical methods, photo-initiated coupling has also been used to covalently immobilize AMs onto neural biomaterials. Benefits of this technique include better control over the coupling reaction and also rapid reaction completion (e.g., $\sim$ minutes). Examples of photocoupling include conjugation of benzophenone-derivatized YIGSR to agarose (Borkenhagen et al., 1998) and azidoaniline photocoupling of poly-D-lysine to chitosan (Crompton et al., 2007). As with chemical methods, heterobifunctional crosslinkers can also be employed, as demonstrated by used of an agent with photoreactive and amine-reactive groups to conjugate collagen to agarose (Cullen et al., 2007).

Another interesting alternative to chemical cross-linking is enzymatic coagulation. In this method, an enzyme regulates covalent cross-linking of the AM to the biomaterial matrix. This was demonstrated using fibrin gels, which are formed from fibrinogen in conjunction with the enzyme transglutaminase. Laminin-derived peptides that promote neurite extension were incorporated into the fibrin gel to enhance its inherent cell adhesion properties (Schense et al., 2000).

Each biomaterial modification technique discussed is outlined in Figure 9.

\section{PATTERNING AM-MODIFIED BIOMATERIALS}

Bulk biomaterial modification with AMs increases neuronal adhesion compared to unmodified materials; however, this response is not targeted to specific portions of the material. In addition, AM distribution is not tailored to achieve specific cell responses. There is a substantial body of evidence that suggests neural cells respond to micron and nanoscale features with altered adhesion, proliferation and survival tendencies (Whitesides et al., 2001; Winter, 2006). The focal adhesions characteristic of cell adhesion to the ECM are typically on the order of nanometers (Zaidel-Bar et al., 2004). It is therefore logical that micro- and nanoscale surfaces can better duplicate the in vivo environment and provide more detailed insights into neural cell behavior than bulk-modified materials.

Initial efforts to pattern AMs on neural biomaterials focused on $2 \mathrm{D}$, planar surfaces because of the simplicity of fabrication. In an early example, fluorinated ethylene propylene films were patterned with laminin-derived peptides YIGSR and IKVAV through radio frequency glow discharge (Ranieri et al., 1994). AM patterns can promote specific neuronal responses. For example, AMs have been patterned, along with non-cell adhesive polyethylene glycol (PEG) domains, on activated glass surfaces. The non-cell adhesive regions were created using covalent attachment methods, whereas the cell adhesive domains were created using the shadow masking technique involving $\mathrm{Ti}$ and Au sputter coating followed by AM attachment. The resulting alternating 'stripe' pattern promoted hippocampal neuron alignment and neurite extension along the length of the patterned AM (Figure 10) (Saneinejad and Shoichet, 1998). Similarly, poly(chlorotrifluorothylene) (PCTFE) was also

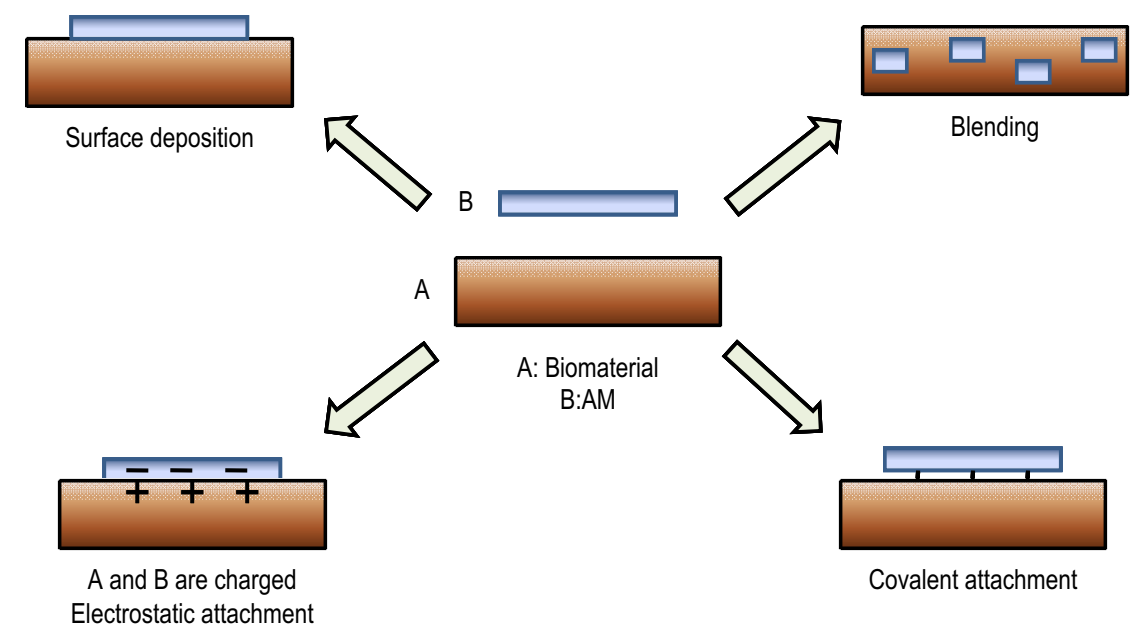

FIGURE 9 | Biomaterial modification techniques. 
used for creating well defined alternating 'stripe' patterns of laminin-derived peptides YIGSR and IKVAV (Saneinejad and Shoichet, 2000).

Most of these early studies examined AM patterning on relatively smooth substrates. More recently, researchers have focused on creating topological patterns on the biomaterial and combining these with AM patterns by physical adsorption or covalent binding. Topological patterns can be created through a variety of techniques. For example, microfluidic patterning has been used to create channels on polymeric surfaces with $\mathrm{O}_{2}$ plasmatreated polydimethylsiloxane (PDMS) molds. These channels can then be modified with AMs through standard bioconjugation methods. For example, avidin-biotin interactions have been exploited to create patterns of IKVAV on PEGPLA (Patel et al., 1998). Specifically, plasma-treated PDMS molds were employed to form patterns on PLA-PEG-biotin surfaces. Avidin solution was then placed on this modified surface resulting in PLA-PEG-biotinavidin. Finally, biotinylated ligands (biotin-AMs) were anchored to the PLA-PEG-biotin via avidin forming PLA-PEG-biotin-avidin-biotin-AM. Photolithography can be used to create 'master' patterns, which can then be transferred to polymeric surfaces by compression molding or similar techniques. This method has been used to modify poly(D, L-lactic acid) with laminin and was used to examine Schwann cell culture (Miller et al., 2001a,b). Microcontact printing has been used to print AMs directly onto biomaterials. For instance, laminin was applied to acrylamide hydrogel surfaces to examine astroglioma and primary rat hippocampal neurons (Hynd et al., 2007).

These methods have primarily been applied to $2 \mathrm{D}$ surfaces. Unfortunately, the in vivo environment is a highly complex $3 \mathrm{D}$ structure, and many target neural biomaterials have been designed to mimic this environment. Alternative methods are needed to create 3D AM patterns in these materials. Hydrogels, one of the most commonly employed 3D materials, can be modified with AMs using photopatterning (especially if vinyl or similar chemistries are employed for the hydrogel backbone; Hahn et al., 2006). Hydrogel

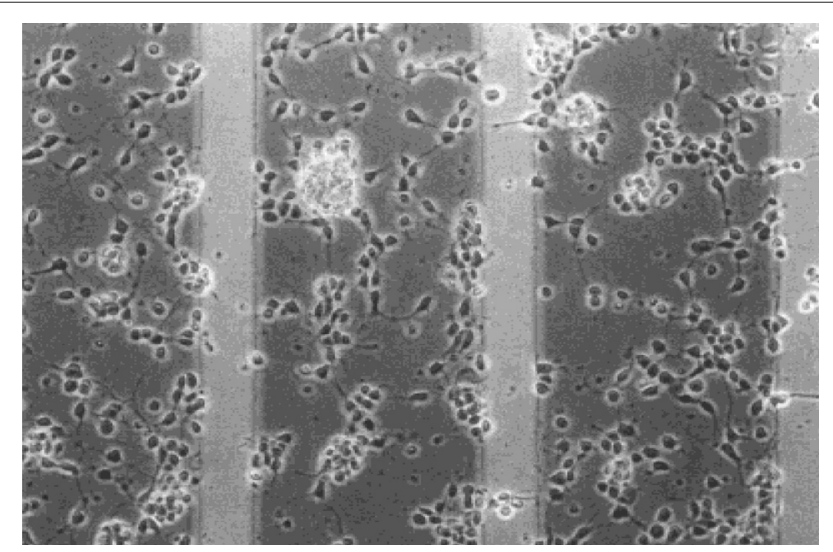

FIGURE 10 | Hippocampal neuron alignment on surface modified glass [CSIKVAV $(200 \mu \mathrm{m}) /$ PEG $(50 \mu \mathrm{m})$ ] at $20 \times$ magnification (Saneinejad and Shoichet, 1998). Reprinted with permission of John Wiley \& Sons, Inc. (C) 1998 John Wiley \& Sons, Inc. patterning has been used to create channels of RGD adhesive peptides in agarose hydrogels (Luo and Shoichet, 2004) using a combination of covalent and photochemical coupling techniques and to study the effect of channel RGD concentration gradients in hyaluronic acid hydrogels (Musoke-Zawedde and Shoichet, 2006). The presence of RGD-modified channels in agarose permitted dorsal root ganglion cells growth and attachment, which was not supported outside the channels (Luo and Shoichet, 2004). High fidelity AM patterns in hydrogels can provide complex topographical and biochemical signals to neurons more closely mimicking the native environment.

\section{CONCLUSIONS}

Biomaterials developed for neural tissue engineering applications should replicate the native brain environment for successful biomaterial-tissue integration. Application of bound/tethered factors or AMs has become one of the primary strategies to achieve this goal. The interaction between the biomaterial and cells is crucial in determining cell fate. Understanding the phenomenon of cell adhesion on biomaterials and the mechanisms by which AMs promote neural adhesion is crucial for the development of materials that promote neural tissue regeneration.

Among the different techniques discussed for creating biomaterial-AM composites, blending and surface deposition are the simplest methods. However, composites created using these techniques are less stable. Electrostatic and covalent attachment techniques can produce much stronger and more stable composites because of stronger attractive forces between the biomaterial and AM. Selection of AM incorporation method should thus be made with the end goal in mind. For example, in vivo implants with an expected lifetime of months to years would require a more stable interface than materials designed for short-term in vitro tests. Additionally, the morphology of AM deposition must be considered. Whereas bulk material modification is easier, patterned AMs have been shown to promote specific neural responses.

AM-modification using these methods has already produced materials for drug delivery, tissue engineering, and implanted neural prostheses. These materials have shown promise in minimizing the long term immune response to implanted materials and in promoting nerve regeneration. However, the stability of AM coatings is still a significant issue. Future enhancements in AMmodification will likely include combinations of the techniques discussed and increases in the number of biomolecules bound. With continued improvement, AM-modification will likely become a critical element in enhancing biomaterial-tissue integration with the nervous system.

\section{ACKNOWLEDGEMENTS}

The authors would like to acknowledge Dr. Ravi Bellamkonda (Georgia Institute of Technology), Dr. Wei He (University of Tennessee), Dr. Tracy Cui (University of Pittsburgh), Dr. Molly Shoichet (University of Toronto), Dr. Jodie Lutkenhaus (Yale University), Nathalie Guimard and Dr. Christine Schmidt (University of Texas at Austin) for providing figures. The authors would also like to acknowledge Elise Ferguson (The Ohio State University) for providing schematics of covalent modification reactions. 


\section{REFERENCES}

Alberts, B., Bray, D., Lewis, B., Raff, M., Roberts, K., and Watson, J. D. (1996). Molecular Biology of the Cell. New York, Garland Publishing, Inc.

Alobaid, N., Salacinski, H. J., Sales, K. M., Hamilton, G., and Seifalian, A. M. (2005). Single stage cell seeding of small diameter prosthetic cardiovascular grafts. Clin. Hemorheol. Microcirc. 33, 209-226.

Aumailley, M., and Gayraud, B. (1998). Structure and biological activity of the extracellular matrix. J. Mol. Med. 76, 253-265.

Bacakova, L., Filova, E., Rypacek, F., Svorcik, V., and Stary, V. (2004). Cell adhesion on artificial materials for tissue engineering. Physiol. Res. 53(Suppl 1), S35-S45.

Bani-Yaghoub, M., Tremblay, R. G., Ajji, A., Nzau, M., Gangaraju, S., Chitty, D., Zurakowski, B., and Sikorska, M. (2008). Neuroregenerative strategies in the brain: emerging significance of bonemorphogenetic protein 7 (BMP7). Biochem. Cell. Biol. 86, 361-369.

Bellamkonda, R., Ranieri, J. P., and Aebischer, P. (1995). Laminin oligopeptide derivatized agarose gels allow three-dimensional neurite extension in vitro. J. Neurosci. Res. 41, 501-509.

Blewitt, M. J., and Willits, R. K. (2007). The effect of soluble peptide sequences on neurite extension on 2D collagen substrates and within $3 \mathrm{D}$ collagen gels. Ann. Biomed. Eng. 35, 2159-2167.

Borkenhagen, M., Clemence, J. F., Sigrist, H., and Aebischer, P. (1998). Three-dimensional extracellular matrix engineering in the nervous system. J. Biomed. Mater. Res. 40, 392-400.

Chen, C. S., Alonso, J. L., Ostuni, E., Whitesides, G. M., and Ingber, D. E. (2003). Cell shape provides global control of focal adhesion assembly. Biochem. Biophys. Res. Commun. 307, 355-361.

Chen, C. S., Mrksich, M., Huang, S., Whitesides, G. M., and Ingber, D. E. (1997). Geometric control of cell life and death. Science 276, 1425-1428.

Chen, C. S., Tan, J., and Tien, J. (2004). Mechanotransduction at cell-matrix and cell-cell contacts. Annu. Rev. Biomed. Eng. 6, 275-302.

Cheng, M., Cao, W., Gao, Y., Gong, Y., Zhao, N., and Zhang,X. (2003).Studies on nerve cell affinity of biodegradable modified chitosan films. J. Biomater. Sci. Polym. Ed. 14, 1155-1167.

Crompton, K. E., Goud, J. D., Bellamkonda, R.V., Gengenbach, T. R., Finkelstein, D. I., Horne, M. K., and Forsythe, J. S. (2007). Polylysine- functionalised thermoresponsive chitosan hydrogel for neural tissue engineering. Biomaterials 28, 441-449.

Cui, X., Lee, V. A., Raphael, Y., Wiler, J. A., Hetke, J. F., Anderson, D. J., and Martin, D. C. (2001). Surface modification of neural recording electrodes with conducting polymer/biomolecule blends. J. Biomed. Mater. Res. $56,261-272$.

Cui, X., Wiler, J., Dzaman, M., Altschuler, R. A., and Martin, D. C. (2003). In vivo studies of polypyrrole/peptide coated neural probes. Biomaterials 24, 777-787.

Cullen, D. K., Lessing, M. C., and LaPlaca, M. C. (2007). Collagendependent neurite outgrowth and response to dynamic deformation in three-dimensional neuronal cultures. Ann. Biomed. Eng. 35, 835-846.

Dhoot, N. O., Tobias, C. A., Fischer, I., and Wheatley, M. A. (2004). Peptidemodified alginate surfaces as a growth permissive substrate for neurite outgrowth. J. Biomed. Mater. Res. A 71, 191-200.

Gandhi, M. R., Murray, P., Spinks, G. M., and Wallace, G. G. (1995). Mechanism of electrochemical actuation in polypyrrole. Synth. Met. 73, 247-256.

Gelse, K., Poschl, E., and Aigner, T. (2003). Collagens - structure, function, and biosynthesis. Adv. Drug Deliv. Rev. 55, 1531-1546.

George,P.M.,Lyckman,A.W.,LaVan, D. A., Hegde, A., Leung, Y., Avasare, R., Testa, C., Alexander, P. M., Langer, R., and Sur, M. (2005). Fabrication and biocompatibility of polypyrrole implants suitable for neural prosthetics. Biomaterials 26, 3511-3519.

Graf, J., Ogle, R. C., Robey, F. A., Sasaki, M., Martin, G. R., Yamada, Y., and Kleinman, H. K. (1987). A pentapeptide from the laminin $\mathrm{B} 1$ chain mediates cell adhesion and binds the 67,000 laminin receptor. Biochemistry 26, 6896-6900.

Guimard, N. K., Gomez, N., and Schmidt, C. E. (2007). Conducting polymers in biomedical engineering. Prog. Polym. Sci. 32, 876-921.

Hahn, M. S., Miller, J. S., and West, J. L. (2006). Three-dimensional biochemi$\mathrm{cal}$ and biomechanical patterning of hydrogels for guiding cell behavior. Adv. Mater. 18, 2679-2684.

Haile, Y., Berski, S., Drager, G., Nobre, A., Stummeyer, K., Gerardy-Schahn, R., and Grothe, C. (2008). The effect of modified polysialic acid based hydrogels on the adhesion and viability of primary neurons and glial cells. Biomaterials 29, 1880-1891.

Harnett, E. M., Alderman, J., and Wood, T. (2007). The surface energy of various biomaterials coated with adhesion molecules used in cell culture. Colloids Surf. B Biointerfaces 55, 90-97.

Hategan, A., Sengupta, K., Kahn, S., Sackmann, E., and Discher, D. E. (2004). Topographical pattern dynamics in passive adhesion of cell membranes. Biophys. J. 87, 3547-3560.

He, W., and Bellamkonda, R. V. (2005). Nanoscale neuro-integrative coatings for neural implants. Biomaterials 26, 2983-2990.

He, W., McConnell, G. C., and Bellamkonda, R. V. (2006). Nanoscale laminin coating modulates cortical scarring response around implanted silicon microelectrode arrays. J. Neural Eng. 3, 316-326.

Heggins, D., and Banker, G. (1998). Primary dissociated cell cultures. In Culturing Nerve Cells, G. Banker and K. Goslin, eds (Cambridge, MIT Press), pp. 37-78.

Hermanson, G. T. (1996). Bioconjugate Techniques. San Diego, Academic Press.

Hersel, U., Dahmen, C., and Kessler, H. (2003). RGD modified polymers: biomaterials for stimulated cell adhesion and beyond. Biomaterials 24 4385-4415.

Hou, S., Xu, Q., Tian, W., Cui, F., Cai, Q. Ma, J., and Lee, I. S. (2005). The repair of brain lesion by implantation of hyaluronic acid hydrogels modified with laminin. J. Neurosci. Methods 148, 60-70.

Huang, Y. C., Huang, C. C., Huang, Y. Y., and Chen, K. S. (2007). Surface modification and characterization of chitosan or PLGA membrane with laminin by chemical and oxygen plasma treatment for neural regeneration. J. Biomed. Mater. Res. A 82 842-851.

Huber, M., Heiduschka, P., Kienle, S., Pavlidis, C., Mack, J., Walk, T., Jung, G. and Thanos, S. (1998). Modification of glassy carbon surfaces with synthetic laminin-derived peptides for nerve cell attachment and neurite growth. $J$. Biomed. Mater. Res. 41, 278-288.

Hynd, M. R., Frampton, J. P., DowellMesfin, N., Turner, J. N., and Shain, W. (2007). Directed cell growth on protein-functionalized hydrogel surfaces. J. Neurosci. Methods 162 255-263.

Hynes, R. O. (1999). Cell adhesion: old and new questions. Trends Cell Biol. 9, M33-M37.

Kam, L., Shain, W., Turner, J. N., and Bizios, R. (2002). Selective adhesion of astrocytes to surfaces modified with immobilized peptides. Biomaterials 23, 511-515.

Kim, D. H.,Abidian, M., and Martin, D. C. (2004). Conducting polymers grown in hydrogel scaffolds coated on neural prosthetic devices. J. Biomed. Mater. Res. A 71, 577-585.

Kleinman,H.K.,Weeks, B.S.,Cannon, F. B., Sweeney, T. M., Sephel, G. C. Clement, B., Zain, M., Olson, M. O., Jucker, M., and Burrous, B. A. (1991). Identification of a $110-\mathrm{kDa}$ nonintegrin cell surface laminin-binding protein which recognizes an A chain neurite-promoting peptide. Arch. Biochem. Biophys. 290, 320-325.

Koh, H. S., Yong, T., Chan, C. K., and Ramakrishna,S. (2008).Enhancement of neurite outgrowth using nanostructured scaffolds coupled with laminin. Biomaterials 29, 3574-3582.

Langer, R., and Vacanti, J.P. (1993). Tissue engineering. Science 260, 920-926.

Lauffenburger, D. A., and Linderman, J. L. (1996). Receptor-mediated cell behavioral responses. In Receptors: Models for Binding, Trafficking, and Signaling, D. A. Lauffenburger and J. L. Linderman, eds (Oxford, Oxford University Press, Inc.), pp. 236-344.

LeBaron, R. G., and Athanasiou, K. A. (2000). Extracellular matrix cell adhesion peptides: functional applications in orthopedic materials. Tissue Eng. 6, 85-103.

Levesque, S. G., and Shoichet, M. S. (2006). Synthesis of cell-adhesive dextran hydrogels and macroporous scaffolds. Biomaterials 27, 5277-5285.

Li, Y., Neoh, K. G., and Kang, E. T. (2005). Controlled release of heparin from polypyrrole-poly(vinyl alcohol) assembly by electrical stimulation. $J$. Biomed. Mater. Res. A 73, 171-181.

Liesi, P., Narvanen, A., Soos, J., Sariola, H., and Snounou, G. (1989). Identification of a neurite outgrowth-promoting domain of laminin using synthetic peptides. FEBS Lett. 244, 141-148.

Luo, Y., and Shoichet, M. S. (2004). A photolabile hydrogel for guided three-dimensional cell growth and migration. Nat. Mater. 3, 249-253.

Lutkenhaus, J. L., and Hammond, P. T. (2007). Electrochemically enabled polyelectrolyte multilayer devices: from fuel cells to sensors. Soft Matter 3, 804-816.

Mahoney, M. J., and Anseth, K. S. (2007). Contrasting effects of collagen and bFGF-2 on neural cell function in degradable synthetic PEG hydrogels. $J$. Biomed. Mater. Res. A 81, 269-278.

Massia, S. P., Holecko, M. M., and Ehteshami, G. R. (2004). In vitro assessment of bioactive coatings for neural implant applications. J. Biomed. Mater. Res. A 68, 177-186.

Miller, C., Jeftinija, S., and Mallapragada, S. (2001a). Micropatterned Schwann cell-seeded biodegradable polymer substrates significantly enhance 
neurite alignment and outgrowth. Tissue Eng. 7, 705-715.

Miller, C., Shanks, H., Witt, A., Rutkowski, G., and Mallapragada, S. (2001b). Oriented Schwann cell growth on micropatterned biodegradable polymer substrates. Biomaterials 22, 1263-1269.

Mingyu, C., Kai, G., Jiamou, L., Yandao, G., Nanming, Z., and Xiufang, Z. (2004). Surface modification and characterization of chitosan film blended with polyL-lysine. J. Biomater. Appl. 19, 59-75.

Musoke-Zawedde, P., and Shoichet, M. S. (2006). Anisotropic three-dimensional peptide channels guide neurite outgrowth within a biodegradable hydrogel matrix. Biomed. Mater. 1, 162-169.

Nakaji-Hirabayashi, T., Kato, K., and Iwata, H. (2008). Self-assembling chimeric protein for the construction of biodegradable hydrogels capable of interaction with integrins expressed on neural stem/progenitor cells. Biomacromolecules 9, 1411-1416.

Park, K. S., Kim, S. M., Kim, M. S., Lee, I., Rhee, J. M., Lee, H. B., and Khang, G. (2008). Effect of cell-adhesivemolecule-coated poly(lactideco-glycolide) film on the cellular behaviors of olfactory ensheathing cells and Schwann cells. J. Appl. Polym. Sci. Symp. 107, 1243-1251.

Patel, N., Padera, R., Sanders, G. H., Cannizzaro, S. M., Davies, M. C., Langer, R., Roberts, C. J., Tendler, S. J., Williams, P. M., and Shakesheff, K. M. (1998). Spatially controlled cell engineering on biodegradable polymer surfaces. FASEB J. 12, 1447-1454.

Peppas,N.A.,Hilt,J.Z.,Khademhosseini, A., and Langer, R. (2006). Hydrogels in Biology and Medicine: from molecular principles to Bionanotechnology. $A d v$. Mater. 18, 1345-1360.

Peyratout, C. S., and Dahne, L. (2004). Tailor-made polyelectrolyte microcapsules: from multilayers to smart containers. Angew. Chem. Int. Ed. Engl. 43, 3762-3783.

Pierschbacher, M. D., and Ruoslahti, E. (1984). Cell attachment activity of fibronectin can be duplicated by small synthetic fragments of the molecule. Nature 309, 30-33.

Poppe, J. (1997). Gelatin. In Thickening and Gelling Agents for Food, A. Imeson, ed (Gaithersburg, MD, Aspen) pp. 144-168.

Rainaldi, G., Calcabrini, A., and Santini, M. T. (1998). Positively charged polymer polylysine-induced cell adhesion molecule redistribution in K562 cells. J. Mater. Sci. Mater. Med. 9, 755-760.

Ranieri, J.P., Bellamkonda, R., Bekos, E. J., Gardella, J. A., Jr., Mathieu, H. J., Ruiz, L., and Aebischer, P. (1994).
Spatial control of neuronal cell attachment and differentiation on covalently patterned laminin oligopeptide substrates. Int. J. Dev. Neurosci. 12, 725-735.

Ratner, B. D., Hoffman, A. S., Schoen, F. J., and Lemons, J.E. (2004). Biomaterials Science: An Introduction to Materials in Medicine. San Diego, CA,Academic Press.

Ruff, R. L., McKerracher, L., and Selzer, M. E. (2008). Repair and neurorehabilitation strategies for spinal cord injury. Ann. N. Y. Acad. Sci. 1142, 1-20.

Saneinejad, S., and Shoichet, M. S. (1998). Patterned glass surfaces direct cell adhesion and process outgrowth of primary neurons of the central nervous system. J. Biomed. Mater. Res. 42, 13-19.

Saneinejad, S., and Shoichet, M. S. (2000). Patterned poly(chlorotrifluoroethyle ne) guides primary nerve cell adhesion and neurite outgrowth. J. Biomed. Mater. Res. 50, 465-474.

Schense, J. C., Bloch, J., Aebischer, P., and Hubbell, J. A. (2000). Enzymatic incorporation of bioactive peptides into fibrin matrices enhances neurite extension. Nat. Biotechnol. 18, 415-419.

Schmidt, C. E., and Leach, J. B. (2003). Neural tissue engineering: strategies for repair and regeneration. Annu. Rev. Biomed. Eng. 5, 293-347.

Schmidt, C. E., Shastri, V. R., Vacanti, J. P., and Langer, R. (1997). Stimulation of neurite outgrowth using an electrically conducting polymer. Proc. Natl. Acad. Sci. U.S.A. 94, 8948-8953.

Shaw, D., and Shoichet, M. S. (2003). Toward spinal cord injury repair strategies: peptide surface modification of expanded poly(tetrafluoroethylene) fibers for guided neurite outgrowth in vitro. J. Craniofac. Surg. 14, 308-316.

Skubitz, A. P., McCarthy, J. B., Zhao, Q., Yi, X. Y., and Furcht, L. T. (1990). Definition of a sequence, RYVVLPR, within laminin peptide F-9 that mediates metastatic fibrosarcoma cell adhesion and spreading. Cancer Res. 50, 7612-7622.

Song, H. K., Toste, B., Ahmann, K., Hoffman-Kim, D., and Palmore, G. T. (2006). Micropatterns of positive guidance cues anchored to polypyrrole doped with polyglutamic acid: a new platform for characterizing neurite extension in complex environments. Biomaterials 27, 473-484.

Spinks, G. M., Campbell, T. E., and Wallace, G. G. (2005a). Force generation from polypyrrole actuators. Smart Mater. Struct. 14, 406-412.

Spinks, G. M., Xi, B., Troung, V.-T., and Wallace, G. G. (2005b). Actuation behaviour of layered composites of polyaniline, carbon nanotubes and polypyrrole. Synth. Met. 151, 85-91.

Stabenfeldt, S. E., Garcia, A. J., and LaPlaca, M.C.(2006). Thermoreversible laminin-functionalized hydrogel for neural tissue engineering. J. Biomed. Mater. Res. A 77, 718-725.

Stauffer, W. R., and Cui, X. T. (2006) Polypyrrole doped with 2 peptide sequences from laminin. Biomaterials 27, 2405-2413.

Suzuki, M., Itoh, S., Yamaguchi, I., Takakuda, K., Kobayashi, H., Shinomiya, K., and Tanaka, J. (2003). Tendon chitosan tubes covalently coupled with synthesized laminin peptides facilitate nerve regeneration in vivo. J. Neurosci. Res. 72, 646-659.

Tang, Z., Wang, Y., Podsiadlo, P., and Kotov, N.A. (2006). Biomedical applications of layer-by-layer assembly: from biomimetics to tissue engineering. Adv. Mater. 18, 3203-3224.

Tian, W. M., Hou, S. P., Ma, J., Zhang, C. L., Xu, Q. Y., Lee, I. S., Li, H. D., Spector, M., and Cui, F. Z. (2005) Hyaluronic acid-poly-D-lysine-based three-dimensional hydrogel for traumatic brain injury. Tissue Eng. 11, 513-525.

Tong, Y. W., and Shoichet, M. S. (1998a). Enhancing the interaction of central nervous system neurons with poly(tetrafluoroethylene-cohexafluoropropylene) via a novel surface amine-functionalization reaction followed by peptide modification. J. Biomater. Sci. Polym. Ed. 9, 713-729.

Tong, Y. W., and Shoichet, M. S. (1998b). Peptide surface modification of poly(tetrafluoroethylene-co-hexafluoropropylene) enhances its interaction with central nervous system neurons. J. Biomed. Mater. Res. 42, 85-95.

Tong, Y. W., and Shoichet, M. S. (2001). Enhancing the neuronal interaction on fluoropolymer surfaces with mixed peptides or spacer group linkers. Biomaterials 22, 1029-1034.

Venstrom, K. A., and Reichardt, L. F. (1993). Extracellular matrix. 2: role of extracellular matrix molecules and their receptors in the nervous system. FASEB J. 7, 996-1003.

Vogel, W. F. (2001). Collagen-receptor signaling in health and disease. Eur. J. Dermatol. 11, 506-514.

Whitesides, G.M.,Ostuni,E., Takayama, S. Jiang, X., and Ingber, D. E. (2001). Soft lithography in biology and biochemistry. Annu. Rev. Biomed. Eng. 3 , 335-373.

Willerth, S.M., and Sakiyama-Elbert, S. E. (2007). Approaches to neural tissue engineering using scaffolds for drug delivery. Adv. Drug Deliv. Rev. 59, 325-338.
Winter, J. O. (2006). Nanoparticles and nanowires for cellular engineering. In Tissue, Cell and Organ Engineering, Vol. 9, C. S. Kumar, ed (Weinhem, Wiley VHC), pp. 388-460

Wu, Z. R., Ma, J., Liu, B. F., Xu, Q. Y., and Cui, F.Z. (2007). Layer-by-layer assembly of polyelectrolyte films improving cytocompatibility to neural cells. J. Biomed. Mater. Res. A 81A, 355-362.

Xiao, Y., Martin, D. C., Cui, X., and Shenai, M. (2006). Surface modification of neural probes with conducting polymer poly(hydroxymethylated3,4-ethylenedioxythiophene) and its biocompatibility. Appl. Biochem. Biotechnol. 128, 117-130.

Yavin,E., and Yavin, Z. (1974). Attachment and culture of dissociated cells from rat embryo cerebral hemispheres on polylysine-coated surface. J. Cell Biol. $62,540-546$.

Young, S., Wong, M., Tabata, Y., and Mikos, A. G. (2005). Gelatin as a delivery vehicle for the controlled release of bioactive molecules. J. Control. Release 109, 256-274.

Yu, L. M., Kazazian, K., and Shoichet, M. S. (2007). Peptide surface modification of methacrylamide chitosan for neural tissue engineering applications. $J$. Biomed. Mater. Res. A 82, 243-255.

Yu, L. M. Y., Leipzig, N. D., and Shoichet, M. S. (2008). Promoting neuron adhesion and growth. Mater. Today 11,36-43.

Yu, T. T., and Shoichet, M. S. (2005). Guided cell adhesion and outgrowth in peptide-modified channels for neural tissue engineering. Biomaterials 26 , 1507-1514.

Zaidel-Bar, R., Cohen, M., Addadi, L., and Geiger, B. (2004). Hierarchical assembly of cell-matrix adhesion complexes. Biochem. Soc. Trans. 32, 416-420.

Conflict of Interest Statement: The authors declare that the research was conducted in the absence of any commercial or financial relationships that could be construed as a potential conflict of interest.

Received: 15 January 2009; paper pending published: 23 February 2009; accepted: 07 May 2009; published: 09 June 2009.

Citation: Rao SS and Winter JO (2009) Adhesion molecule-modified biomaterials for neural tissue engineering. Front. Neuroeng. (2009) 2:6. doi:10.3389/neuro.16.006.2009

Copyright $\odot 2009$ Rao and Winter. This is an open-access article subject to an exclusive license agreement between the authors and the Frontiers Research Foundation, which permits unrestricted use, distribution, and reproduction in any medium, provided the original authors and source are credited. 